\title{
Durability of Interior Renderings in Schools: Optimization of Envelope Insulation for Mitigation of Mould Growth Risk
}

\author{
N. M. M. Ramos, I. M. Ribeiro, J. M. P. Q. Delgado \\ and V. P. de Freitas
}

\begin{abstract}
A high standard education is, nowadays, a clear objective for any modern society. In Portugal, the retrofit of educational buildings has an enormous relevance as demonstrated by the "Program for Retrofit and Upgrade of High Schools". Educational buildings specific characteristics such as high occupancy rates and high amount of time children spend in classrooms make them a special case compared to other buildings. Mould growth on envelope surfaces is frequently observed in these buildings, reducing the expected durability of renderings and coatings. The present work consisted of two main lines of research: one of simulation and other of optimization. The simulation part included modelling of Interior Surfaces Temperature, Indoor Air Temperature and Relative Humidity variation, before and after a hypothetical retrofit process. Optimization techniques were applied in the definition of insulation thickness to be numerically tested in the "after retrofit" scenario. The objective was to minimise insulation thickness in each building element of the envelope. The constraints were derived from the control of surface temperature values that would result in mould growth risk.
\end{abstract}

Keywords Building retrofitment - Hygrothermal behaviour - Mould • Optimization

N. M. M. Ramos $(\bowtie)$ · I. M. Ribeiro · J. M. P. Q. Delgado · V. P. de Freitas LFC-Building Physics Laboratory, Civil Engineering Department Faculty of Engineering, University of Porto, 4200-465 Porto, Portugal e-mail: nuno.ramos@fe.up.pt

I. M. Ribeiro

e-mail: iribeiro@fe.up.pt

J. M. P. Q. Delgado

e-mail: jdelgado@fe.up.pt

V. P. de Freitas

e-mail: vpfreita@fe.up.pt 


\section{Introduction}

A high standard education is, nowadays, a clear objective for any modern society. In Portugal, the retrofit of educational buildings has an enormous relevance as demonstrated by the "Program for Retrofit and Upgrade of High Schools" [1]. The retrofit of the first 205 schools represents an investment of 2,500 million Euros, intending for them to respond to present demands namely energy efficiency, comfort, indoor air quality (IAQ) and functional organization [2, 3].

In Portugal, as in European countries, educational buildings share many similar design, operation and maintenance features. Educational buildings specific characteristics such as high occupancy rates and high amount of time children spend in classrooms make them a special case compared to other buildings [4]. Therefore, the retrofit process should take into account the high internal heat gains due to high occupancy rates, the high solar gains due to glazing and the demanding needs for ventilation and IAQ [5, 6]. The regulations adopted in recent years were thought for new buildings and not for the retrofit of existing ones. Therefore their implementation may not lead to intended objectives. On the other hand, the costs for satisfying the demands are so high and imply such intrusive interventions that justify a careful technical reflexion.

Durability issues are also of main importance when looking at intensively used buildings. Considerable work has been internationally carried out in the area of durability and service life prediction as requisite tools for helping assess long-term effects for maintenance of building envelope systems, envelope components and related materials. Increasingly, building material and component manufacturers are seeking systematic methods to assess the likely risk to premature deterioration of existing products given specific climatic effects, or the most vulnerable exposure conditions of new products in specified systems. The importance of these aspects is reflected in several initiatives and activities at international level. For example, the joint CIB W080/RILEM Committees (71-PSL, 100-TSL and 140-TSL) have been responsible to help develop the necessary guides, methods, and techniques that will enable practitioners to select the appropriate tools to predict service life [7].

In this work, the focus was put on degradation of inside surfaces due to mould growth. This is a common problem in some existing Portuguese buildings due to the combination of a mild humid climate, discontinuous heating, adventitious ventilation and low quality envelope.

The objective of this work is to find the optimal insulation thickness to be added to envelope components regarding mould growth mitigation. Two major constraints were elected to conduct the optimization process. The resulting thermal resistance of walls and ceiling should prevent mould growth by avoiding surface condensation and contribute to the increase of minimum indoor temperature admitting no additional heating is available. It should be taken into account that due to high internal gains in classrooms and mild climate Portuguese conditions it may be possible, in some cases, to avoid additional heating. Also, due to economic restraints, adequate heating regarding comfort may not be implemented. The result 
of this optimization process should therefore be regarded as a safety net for the envelope, rather than the ideal solution for a properly operated building.

The demand for energy efficiency and IAQ has lead to solutions where the passive behaviour of the building becomes of minor importance when compared to systems. But for technical or economic reasons the full operation of the systems may be impossible and therefore the evaluation of the building performance for that scenario must be investigated.

The present work consisted of two main lines of research: one of simulation and other of optimization. The simulation was focused on the hygrothermal behaviour of a classroom using a simplified model developed by the authors. The EnergyPlus software $[8,9]$ was used to simulate the same scenarios, providing results for comparison. The optimization process was adapted to the simplified model since it uses linear functions.

\section{Design Problem}

Figure 1 presents a 3D model of the studied building, which is part of a school built on the late 1970s. This specific building holds two classrooms that have simultaneous occupation and can therefore be approximated with a one zone model.

The building envelope (Figs. 2 and 3) is composed of $15 \mathrm{~cm}$ concrete walls (Fig. 4), single glazed aluminium frame windows (Fig. 5) and a flat roof composed by a $25 \mathrm{~cm}$ concrete slab protected by cement-fibre plates. No thermal insulation

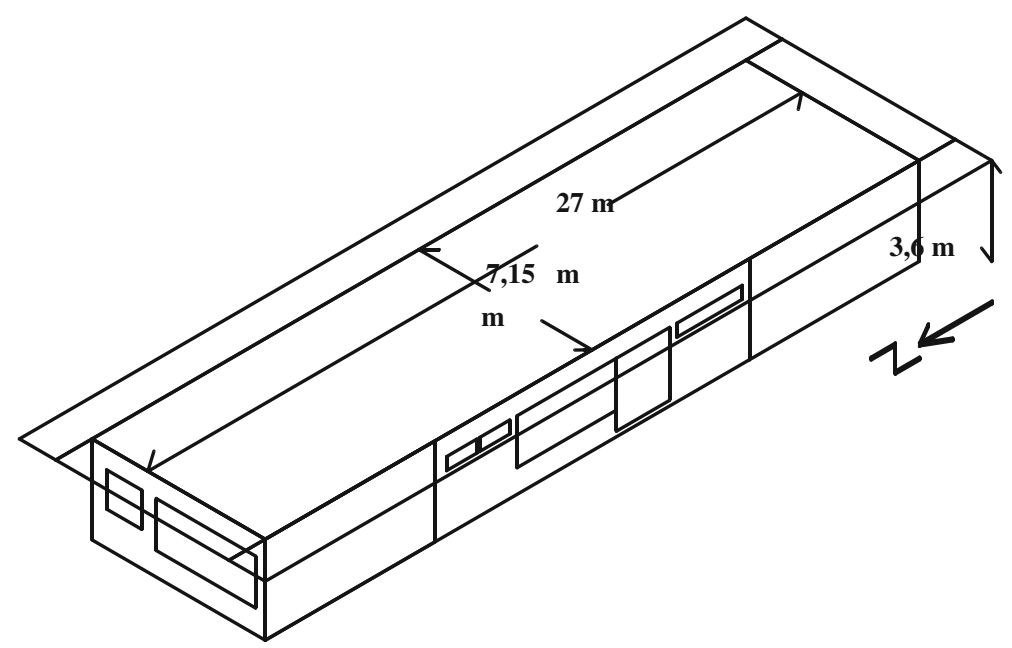

Fig. 1 Sketch of the building analyzed 


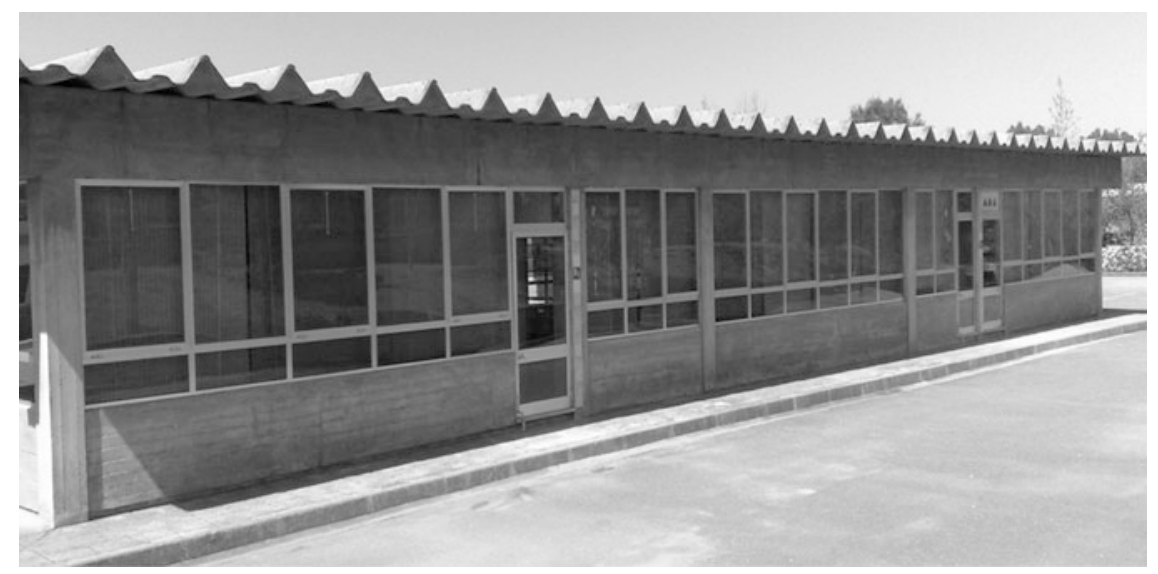

Fig. 2 School building's East façade

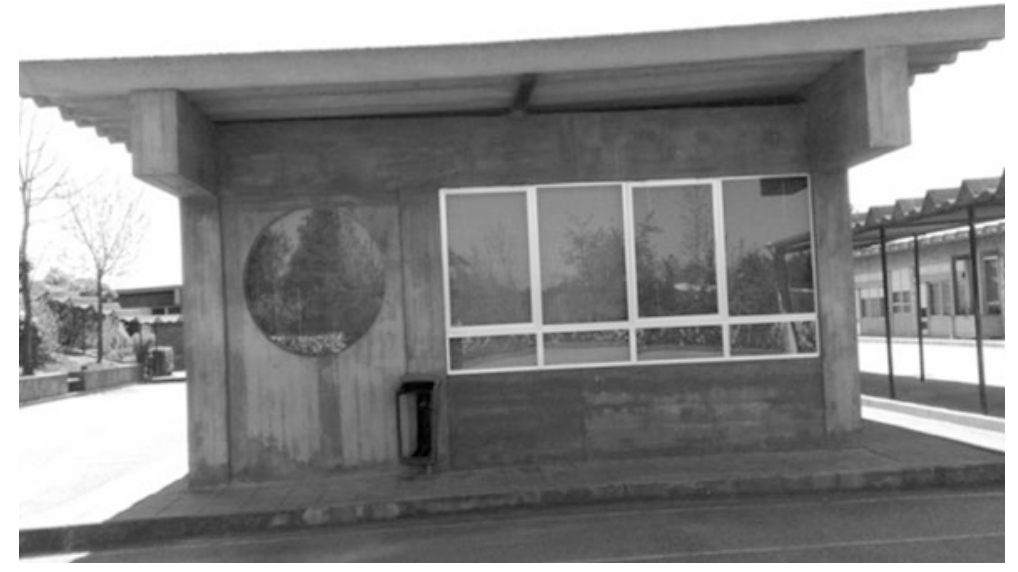

Fig. 3 School building's north façade

was originally applied in the envelope opaque elements. The interior surfaces of those elements were often affected by mould growth (Fig. 6).

The building is located in Porto, in the so-called Warm-Summer-Mild-Winter zone. The exterior temperature will not drop below $0{ }^{\circ} \mathrm{C}$ and may reach $30{ }^{\circ} \mathrm{C}$ in the summer. The average temperature in January is $7.5^{\circ} \mathrm{C}$. For simulation purposes, the TMY format weather file for Porto, available on the Energy Plus web page, was used (Fig. 7).

The occupation of the two classrooms corresponds to a total of 50 persons with a metabolic rate of $70 \mathrm{~W} / \mathrm{m}^{2}$ (ISO 7730, [10]), in a schedule 8.30-13.00 and 14.00-18.30. No mechanical ventilation was applied in the original classrooms, therefore relying on adventitious ventilation and window opening by users. But 
Fig. 4 Building façade

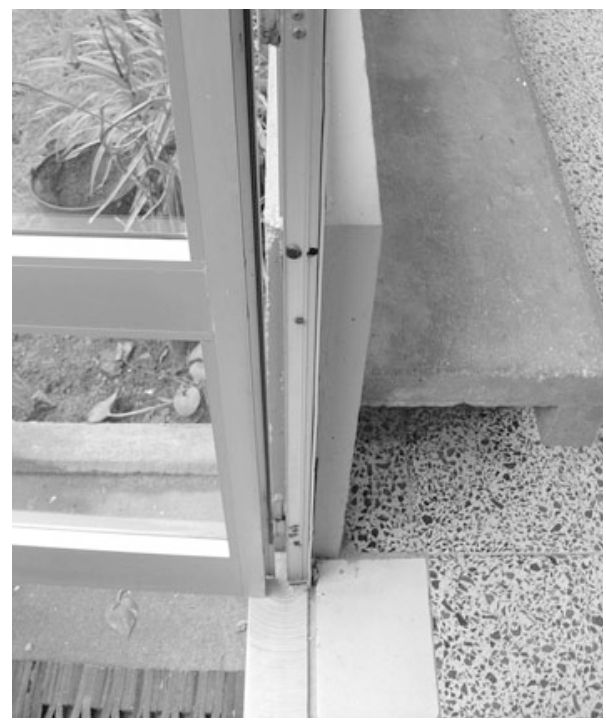

since the new regulations [3] demand $30 \mathrm{~m}^{3} / \mathrm{h}$ per person, it was admitted in all calculations that, when occupied, an ach $=2.2 \mathrm{~h}^{-1}$ would prevail and, in the remaining periods, ach would drop to $0.6 \mathrm{~h}^{-1}$.

The difference between the scenarios of pre or post retrofit was the insulation thickness added to the envelope elements. In this exercise, XPS $\left[0.035 \mathrm{~W} /\left(\mathrm{m}^{2 \circ} \mathrm{C}\right)\right]$ was considered as insulation material, applied on interior surfaces.

\section{Numerical and Optimization Model}

For these calculations an energy simulation needs to be performed to solve the design optimization problem described above. Energy-Plus, a building energy analysis tool was used to simulate the hygrothermal behaviour of the building. The differential equation that define the energy balance of a room is [9]

$$
\begin{aligned}
& C_{z} \frac{d T_{z}}{d t}=\sum_{l=1}^{s l} Q_{l}+\sum_{k=1}^{N s} h_{k} A_{k}\left(T_{s k}-T_{z}\right) \\
& +\sum_{i=1}^{N z o n e s} m_{i} C_{p}\left(T_{z i}-T_{z}\right)+m_{\mathrm{inf}} C_{p}\left(T_{\infty}-T_{z}\right)+Q_{s y s}
\end{aligned}
$$

where $Q$ is the internal gains by convection; $C_{z}\left(d T_{z} / d t\right)$ is the total energy stored in the air in each thermal zone; $h_{k} A_{k}\left(T_{s k}-T_{z}\right)$ is the heat transfer by convection to the surface of the element $k ; m_{i} C_{P}\left(T_{z i}-T_{z}\right)$ is the heat transfer due to outside air infiltration; $m_{\text {inf }} C_{p}\left(T_{\infty}-T_{z}\right)$ is the heat transfer between different thermal zones and $Q_{\text {sys }}$ is the heat transfer by the building outlet air. 
Fig. 5 Windows

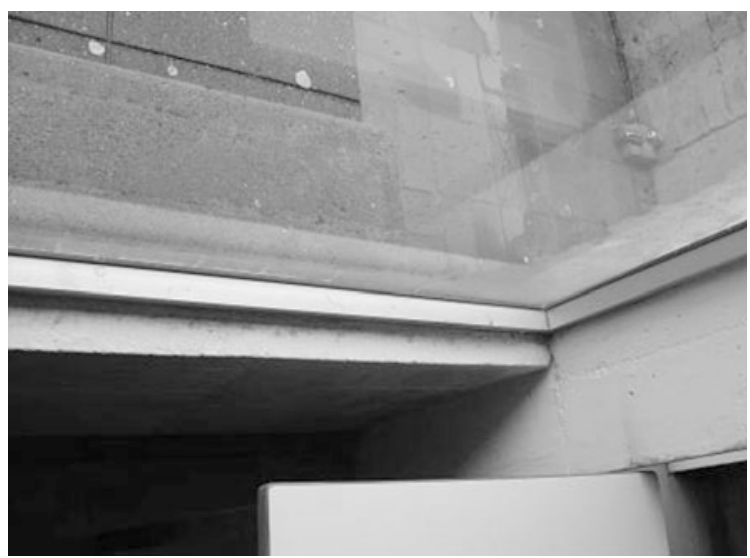

Fig. 6 Mould growth in interior surfaces of the envelope

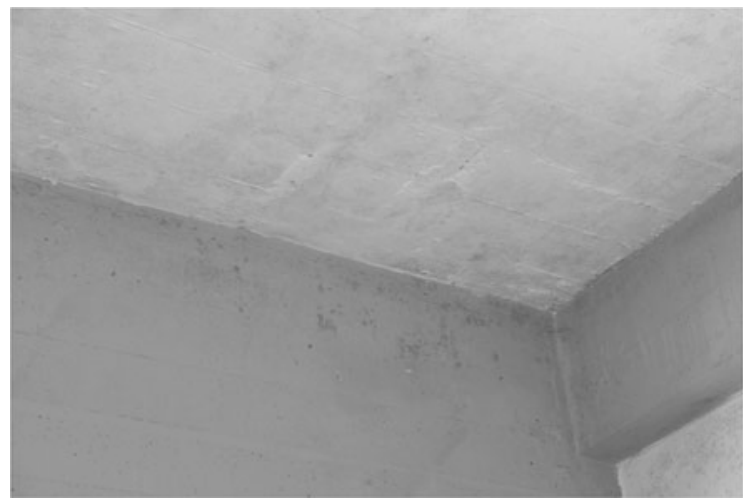

The above differential equation is solved numerically in Energy-Plus using an explicit finite difference scheme, resulting in Eq. (2) for the energy balance.

$$
\begin{gathered}
T_{z}^{t}=\frac{\sum_{l=1}^{s l} Q_{l}^{t}+\sum_{k=1}^{N s} h_{k} A_{k} T_{s k}^{t}+\sum_{i=1}^{N z o n e s} m_{i} C_{p} T_{z i}^{t}+m_{\mathrm{inf}} C_{p} T_{\infty}^{t}+m_{s y s} C_{p} T_{\text {sup }}^{t}}{\left(\frac{11}{6}\right) \frac{C_{z}}{\delta t}+\sum_{i=1}^{N s} h_{i} A_{i}+\sum_{i=1}^{N z o n e s} m_{i} C_{p}+m_{\mathrm{inf}} C_{p}+m_{s y s} C_{p}} \\
-\frac{\left(\frac{C_{z}}{\delta t}\right)\left(-3 T_{z}^{t-\delta t}+\frac{3}{2} T_{z}^{t-2 \delta t}-\frac{1}{3} T_{z}^{t-3 \delta t}\right)}{\left(\frac{11}{6}\right) \frac{C_{z}}{\delta t}+\sum_{i=1}^{N s} h_{i} A_{i}+\sum_{i=1}^{N z o n e s} m_{i} C_{p}+m_{\mathrm{inf}} C_{p}+m_{s y s} C_{p}}
\end{gathered}
$$

The inside superficial temperature is given by

$$
\frac{\rho C_{p} \Delta x\left(T_{k}^{t}-T_{k}^{t-\delta t}\right)}{\delta t}=\frac{\lambda\left(T_{k-1}^{t}-T_{k}^{t}\right)}{\Delta x}+\frac{\lambda\left(T_{k+1}^{t}-T_{k}^{t}\right)}{\Delta x}
$$




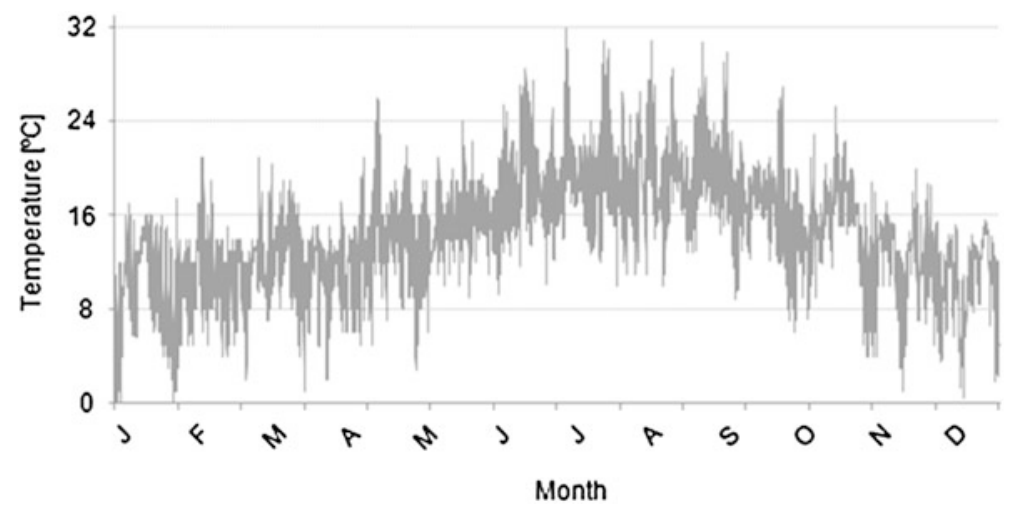

Fig. 7 Outdoor temperature

The aim of this study is to optimize the thickness of thermal insulation to be added in the retrofit process of the building envelope. The model seeks an optimal solution corresponding to the minimum use of the thickness of the different elements (concrete, glass and insulation) so that, without additional climatization:

- indoor air temperature throughout the whole occupation period is between the recommended values of comfort

$$
T_{\text {com }} \leq T_{z}^{t} \leq 25^{\circ} C, \text { if } \sum_{l=1}^{s l} Q_{l}^{t}>0 \text { for all } t \in\{1, \ldots N t\}
$$

- occurrence of surface condensation is not allowed

$$
T_{s i}^{t} \geq T_{d p}^{t} \text { for all } k \in\{1, \ldots N p\} ; \text { and } t \in\{1, \ldots N t\} ;
$$

Since each interface between materials (concrete, glass and insulation) is a node with a predictable heat flow, it is necessary to include equations for its calculation. These equations result from Eq. (3) with the necessary modifications to the conditions of the school built. In this model, some simplifications have been taken into account. One such simplification is related to the thickness of the elements. In this study, the thickness of concrete and glass surfaces are given, while for each opaque surface the optimized thickness of thermal insulation takes the same value.

\subsection{Case I: Model Without Solar Gains}

The gains associated with solar radiation, an important factor of energy balance, were not included in the model. Thus, the energy balance obtained during the optimization process will only be adequate for colder days, usually associated with 
cloudy sky and rain, in which solar gains are negligible. The last simplification is the consideration of the internal gains by convection as an average value throughout the year, i.e., the values of the gains due to occupancy and lighting are considered as an average value during periods with occupation. All these considerations lead to the following nonlinear program: (P1) Minimize,

$$
\sum_{i=1}^{N p} A_{i}\left(x_{i}^{i n s}+x_{i}^{c o n}\right)+\sum_{j=N_{p}+1}^{N s} A_{j} x_{j}^{\text {glas }}
$$

subject to

$$
\begin{gathered}
T_{z}^{t}=\frac{\sum_{l=1}^{s l} Q_{l}^{t}+\sum_{k=1}^{N s} h_{k} A_{k} T_{s k}^{t}+m_{\mathrm{inf}} C_{p} T_{\infty}^{t}-\left(\frac{C_{z}}{\delta t}\right)\left(-3 T_{z}^{t-\delta t}+\frac{3}{2} T_{z}^{t-2 \delta t}-\frac{1}{3} T_{z}^{t-3 \delta t}\right)}{\left(\frac{11}{6}\right) \frac{C_{z}}{\delta t}+\sum_{k=1}^{N s} h_{k} A_{k}+m_{\mathrm{inf}} C_{p}} \\
\rho^{\text {con }} C_{p}^{\text {con }}\left(x_{i}^{\text {con }}\right)^{2} x_{i}^{\text {ins }}\left(T_{\text {coni }}^{t}-T_{\text {coni }}^{t-\delta t}\right)=\left[\lambda^{\text {con }} x_{i}^{\text {ins }}\left(T_{\infty}^{t}-T_{\text {coni }}^{t}\right)+\lambda^{\text {ins }} x_{i}^{\text {con }}\left(T_{s i}^{t}-T_{\text {coni }}^{t}\right)\right] \delta t \\
\rho^{\text {ins }} C_{p}^{\text {ins }}\left(x_{i}^{\text {ins }}\right)^{2}\left(T_{s i}^{t}-T_{s i}^{t-\delta t}\right)=\left[\lambda^{\text {ins }}\left(T_{c o n i}^{t}-T_{s i}^{t}\right)+h_{i} x_{i}^{\text {ins }}\left(T_{z}^{t}-T_{s i}^{t}\right)\right] \delta t \\
\rho^{\text {glas }} C_{p}^{\text {glas }}\left(x_{j}^{\text {glas }}\right)^{2}\left(T_{s j}^{t}-T_{s j}^{t-\delta t}\right)=\left[\lambda^{\text {glas }}\left(T_{\infty}^{t}-T_{s j}^{t}\right)+h_{j}\left(T_{z}^{t}-T_{s j}^{t}\right)\right] \delta t \\
T_{s i}^{t} \geq T_{d p}^{t} ; T_{\text {com }} \leq T_{z}^{t} \leq 25^{\circ} C, \text { if } \sum_{l=1}^{s l} Q_{l}^{t}>0 \\
x_{i}^{\text {ins }} \geq 0, \quad x_{i}^{\text {con }} \geq 0, \quad x_{j}^{\text {glas }} \geq 0
\end{gathered}
$$

with $i \in\{1, \ldots, N p\}, j \in\{N p+1, \ldots, N s\}, k \in\{1, \ldots, N s\}, l \in\{1, \ldots, s l\}$ and $t \in\{1, \ldots, N t\}$.

The meaning of all parameters in this problem is presented below:

$-N_{t}$ is the number of time intervals analysed;

$-N_{p}$ is the number of opaque elements;

- $N_{s}$ is the number of surface;

- $(N s-N p)$ is the number of glass elements;

- $\delta t$ is the time interval considered;

- $Q_{l}^{t}$ is the internal gains at time $t$;

$-h_{k}$ is the transfer coefficient of the surface $k$;

$-A_{k}$ is the area of surface $k$;

- $m_{\text {inf }}$ is the infiltrated air mass;

- $T_{\infty}{ }^{t}$ is the outside air temperature at time $t$;

- $C / \delta t$ is the total amount of energy in the air during $\delta t$;

- $T_{z}^{0}$ is the average air temperature inside the 1 st instant before the instant 1 ; 
$-T_{z}^{-1}$ is the average air temperature inside the 2 nd instant before the instant 1 ;

$-T_{z}{ }^{-2}$ is the average air temperature inside the 3 rd instant before the instant 1 ;

$-\rho^{m}$ is the density of material $m$;

- $C_{P}{ }^{m}$ is the specific heat capacity of material $m$;

- $T_{d p}$ is the dew point temperature;

- $T_{\text {com }}$ is the comfort temperature;

$-x_{i}^{m}$ is the thickness of material $m$ (con or glas) of surface $i$;

$-\lambda^{m}$ is the thermal conductibility of material $m$.

The variables have the following meaning:

$-x_{i}^{i n s}$ is the thickness of thermal insulation of opaque element $i$

$-T_{z}^{t}$ is the indoor air temperature at time instant $t$;

- $T_{s k}{ }^{t}$ is the indoor superficial temperature of surface $k$ at time instant $t$.

Note that $T_{z}^{t-k \delta t}$ is the average air temperature inside the $k^{\text {st }}$ instant before the instant $t$.

\subsection{Case II: Model with Solar Gains}

The gains associated with solar radiation were included in a second version of the optimization model. The possibility of an optimization of the window thermal resistance was also considered in this model. The aim of this study was therefore to optimize the thickness of thermal insulation to be added in the retrofit process and an eventual replacement of windows of the building envelope. The model seeks an optimal solution corresponding to the minimum cost of the different elements (windows and insulation). The model underlying can be formulated as the following nonlinear program:

$$
\text { (P2) Minimize: } \sum_{i=1}^{N p} A_{i}\left(x_{i}^{i n s} V^{i n s}\right)+\sum_{j=N_{p}+1}^{N s} A_{j} V_{U}^{w i n}
$$

subject to

$$
T_{z}^{t}=\frac{\sum_{l=1}^{s l} Q_{l}^{t}+\sum_{k=1}^{N s} h_{k} A_{k} T_{s k}^{t}+m_{\mathrm{inf}} C_{p} T_{\infty}^{t}-\left(\frac{C_{z}}{\delta t}\right)\left(-3 T_{z}^{t-\delta t}+\frac{3}{2} T_{z}^{t-2 \delta t}-\frac{1}{3} T_{z}^{t-3 \delta t}\right)}{\left(\frac{11}{6}\right) \frac{C_{z}}{\delta t}+\sum_{k=1}^{N s} h_{k} A_{k}+m_{\mathrm{inf}} C_{p}}
$$

$\rho^{\text {con }} C_{p}^{c o n}\left(x_{i}^{c o n}\right)^{2} x_{i}^{\text {ins }}\left(T_{\text {coni }}^{t}-T_{\text {coni }}^{t-\delta t}\right)=\left[\lambda^{\text {con }} x_{i}^{\text {ins }}\left(T_{\infty}^{t}-T_{\text {coni }}^{t}\right)+\lambda^{i n s} x_{i}^{c o n}\left(T_{\text {si }}^{t}-T_{\text {coni }}^{t}\right)\right] \delta t$ 


$$
\begin{gathered}
\rho^{\text {ins }} C_{p}^{\text {ins }}\left(x_{i}^{\text {ins }}\right)^{2}\left(T_{s i}^{t}-T_{s i}^{t-\delta t}\right)=\left[\lambda^{i n s}\left(T_{\text {coni }}^{t}-T_{s i}^{t}\right)+h_{i} x_{i}^{\text {ins }}\left(T_{z}^{t}-T_{s i}^{t}\right)+x_{i}^{\text {ins }} \frac{R D^{t}}{\sum_{i=1}^{N p} A_{i}}\right] \delta t \\
\rho^{\text {glas }} C_{p}^{\text {glas }}\left(x_{j}^{\text {glas }}\right)^{2}\left(T_{s j}^{t}-T_{s j}^{t-\delta t}\right)=\left[\frac{x_{j}^{\text {glass }}}{\frac{1}{U}-0.17}\left(T_{\infty}^{t}-T_{s j}^{t}\right)+h_{j}\left(T_{z}^{t}-T_{s j}^{t}\right)\right] \delta t \\
T_{s i}^{t} \geq T_{d p}^{t} ; T_{\text {com }} \leq T_{z}^{t} \leq 25^{\circ} C, \text { if } \sum_{l=1}^{s l} Q_{l}^{t}>0 \\
x_{i}^{\text {ins }} \geq 0, \quad x_{i}^{\text {con }} \geq 0, \quad x_{j}^{\text {glas }} \geq 0 \\
1 \leq \mathrm{U} \leq 6 \quad(15)
\end{gathered}
$$

with $i \in\{1, \ldots, N p\}, j \in\{N p+1, \ldots, N s\}, k \in\{1, \ldots, N s\}, l \in\{1, \ldots, s l\}$ and $t \in\{1, \ldots, N t\}$.

The parameters incorporated in this new problem are:

- $V^{k}$ is the cost of material $k$;

$-V_{U}^{\text {win }}$ is the cost of window which is a function of $U$;

$-R D^{t}$ is the solar heat gains distributed to wall surface at time instant $t$.

While the only new variable introduced is:

- $U$ the window heat transfer coefficient.

\section{Results and Discussion}

\subsection{Simulation}

The simulation of the building in the pre-retrofit scenario, using Energy Plus, provided a portrait of its hygrothermal behaviour. Energy Plus (Webpage: www.energy-plus.org) is the U.S. DOE building energy simulation program for modelling and optimizing building heating, cooling, lighting, ventilating, and other energy flows. It builds on the most popular features and capabilities of BLAST and DOE-2 but also includes many innovative simulation capabilities such as time steps of less than an hour, modular systems and plant integrated with heat balancebased zone simulation, multizone air flow, thermal comfort, and photovoltaic systems. 


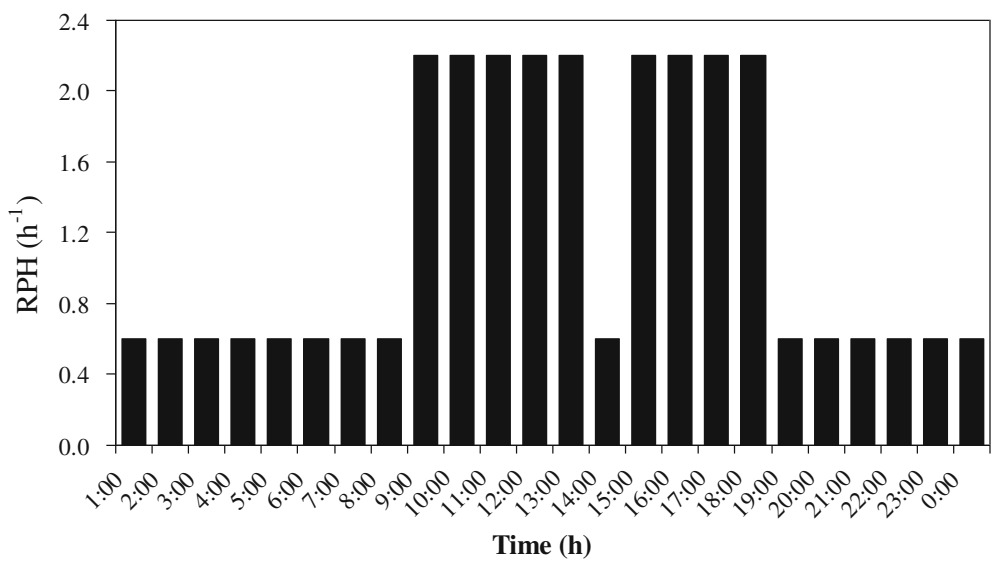

Fig. 8 Adopted schedule for ventilation rates

Its approach is highly detailed in aspects that affect hygrothermal behaviour such as solar gains calculation. The detailed introduction of relevant data is also of importance. Figure 8 presents the adopted schedule for ventilation rates, in the numerical simulations.

Figure 9 presents the indoor temperature variation in January. The existence of heat gains due to users and lighting as well as solar gains, provide a rather small difference between indoor and outdoor temperature. This is caused by the very high ventilation rate considered.

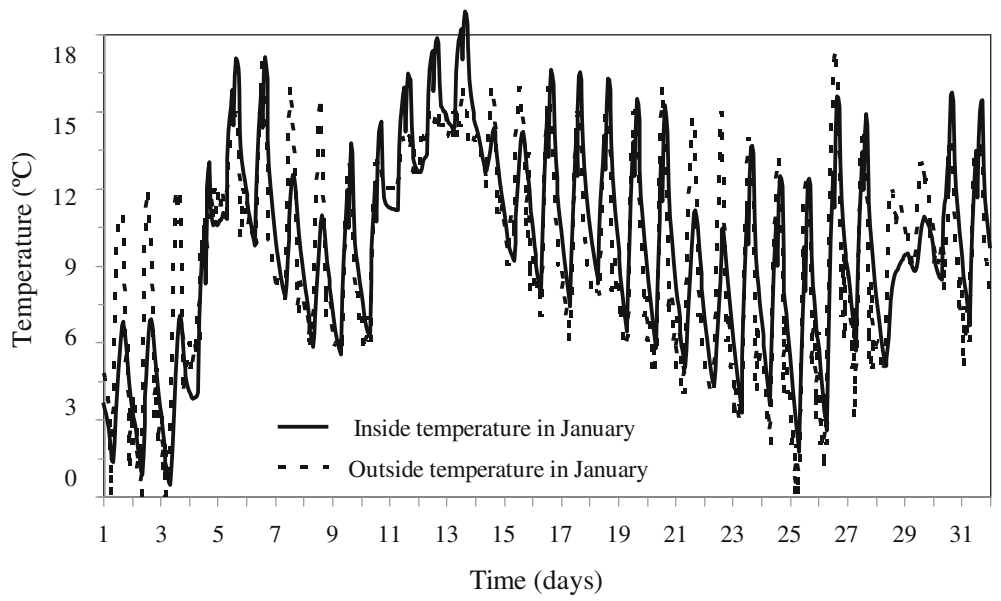

Fig. 9 Temperature variation during January in the pre-retrofit scenario 


\subsection{Optimization}

In this section computational experience is reported on the solution of hydrothermal models by using the nonlinear programs P1 and P2. The commercial program Minos of the GAMS (General Algebraic Modelling System) collection has been used to process these problems [11].

This program developed by Murtagh and Saunders [12] is a specially adapted version of the solver that is used for solving linear and nonlinear programming problems in a GAMS environment [13]. GAMS/MINOS is designed to find solutions that are locally optimal (see Fig. 10). However, if the nonlinear objective and constraint functions are convex within this region, any optimal solution obtained will be a global optimum. Otherwise there may be several local optima, and some of these may not be global. In such cases the chances of finding a global optimum are usually increased by choosing a starting point that is sufficiently close, but there is no general procedure for determining what close means, or for verifying that a given local optimum is indeed global.

\subsubsection{Case I: Model Without Solar Gains}

The application of the Optimization Program (O.P.) to this specific case provided results at different levels. Not only the optimal (local) insulation thickness was spotted but also the evolution of indoor temperature and inside surface temperature was defined by hourly values. As it was possible to have the same temperature values simulated in Energy Plus, using the spotted insulation thickness, the temperature variations obtained in both models could be compared.

One of the days targeted for analysis was January 4, since it was one of the coldest days with occupation. The Optimization Program was run using the two criteria separately. Applying the first criterion, corresponding to the increasing of the inside temperature during winter, O.P. determined an insulation thickness of $4.5 \mathrm{~cm}$. But with this insulation level the increase of indoor temperature for that

Fig. 10 Function with several local optima

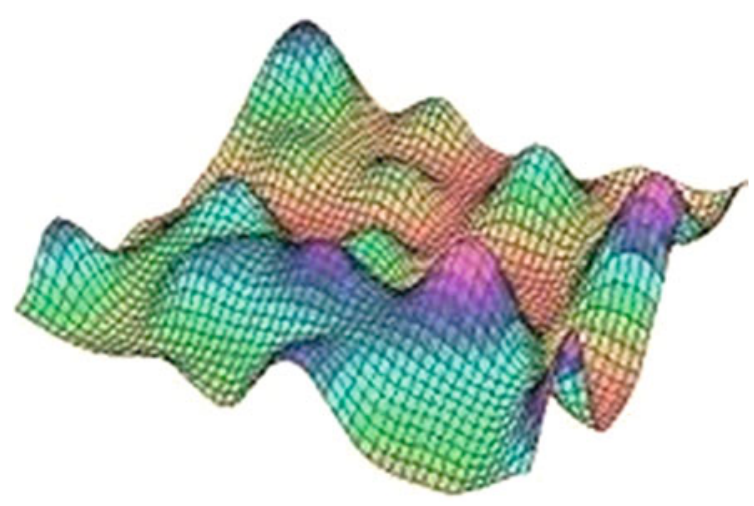


day was less than $2{ }^{\circ} \mathrm{C}$. For higher increments of temperature the problem is infeasible. Using the second criterion for optimization, corresponding to the elimination of surface condensation, the O.P. returned an insulation thickness of $2.4 \mathrm{~cm}$.

The overall conclusion would be that relying only on indoor heat gains and passive behaviour, reaching hygrothermal comfort would be impossible. But the control of surface condensation, however, would be possible, using less than $3 \mathrm{~cm}$ insulation.

The results of the hourly values of temperature obtained in O.P. and Energy Plus were also compared, as presented in Fig. 11. The modelling of January 4 using O.P. provided excellent results, when comparing with the more complete modelling using Energy Plus. The quality of the simulation using O.P. cannot of
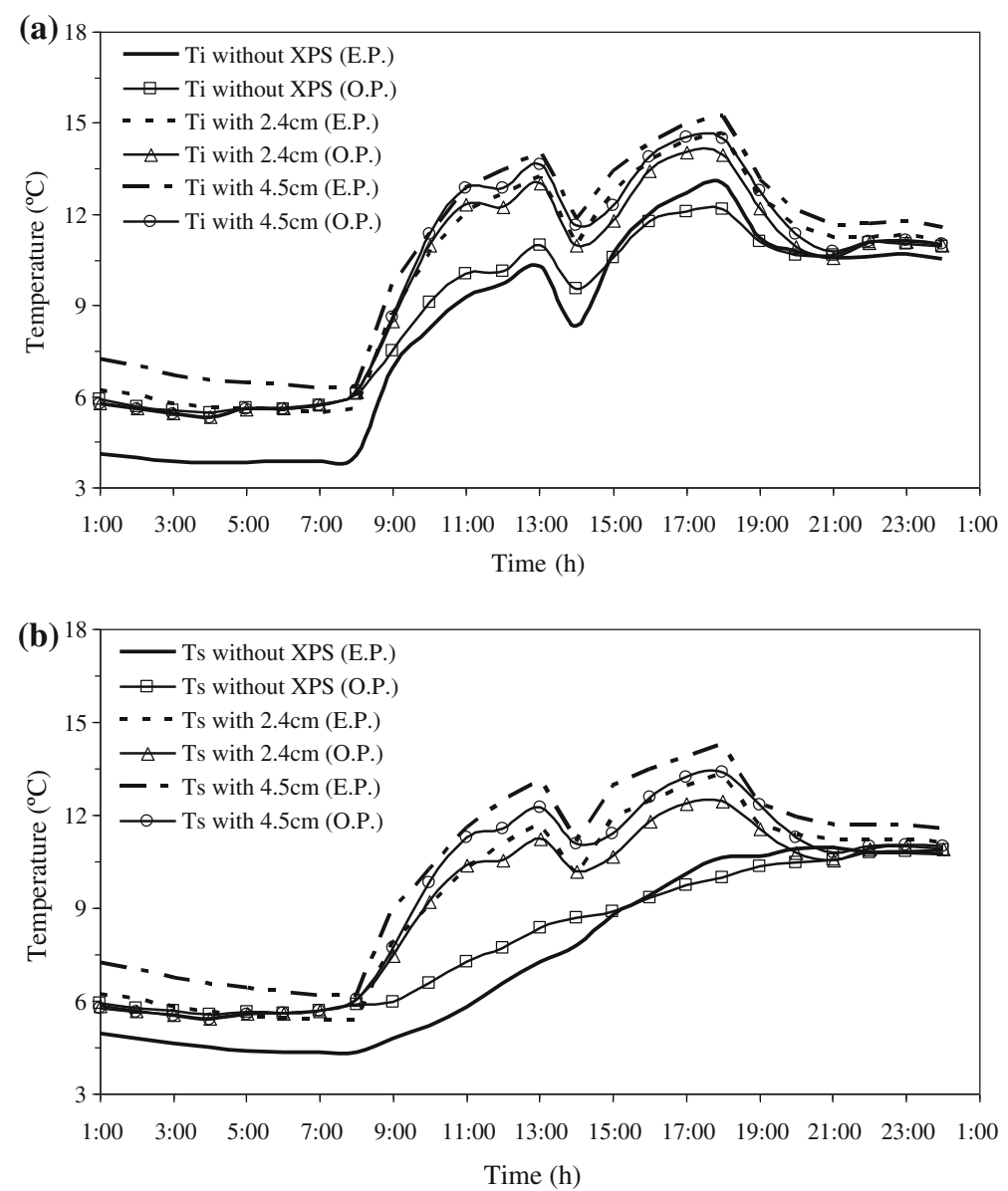

Fig. 11 Evolution of the (a) indoor temperature and (b) superficial indoor temperature on north façade, obtained by the optimization program (O.P.) and energy-plus (E.P.) with different insulation thicknesses, on January 4 
course be achieved for days where high solar radiation prevails. That was the case for January 13 and, as it is presented in Fig. 12, the difference between O.P. and E.P. results is rather large. But winter days with high solar gains present a much lower risk of condensation.

To understand how far the results of O.P. could be interesting for finding an optimal insulation thickness regarding surface condensation control, the building was simulated in E.P. for several thickness values until condensation was eliminated. The results of that simulation are presented in Table 1. The results can be considered in agreement with the ones returned by O.P. if December 29 is disregarded. The comparison for that day is presented in Fig. 13. The graph shows that certain days can lead to an exaggerated value of insulation thickness due to specific hygrothermal behaviour with low overall significance.
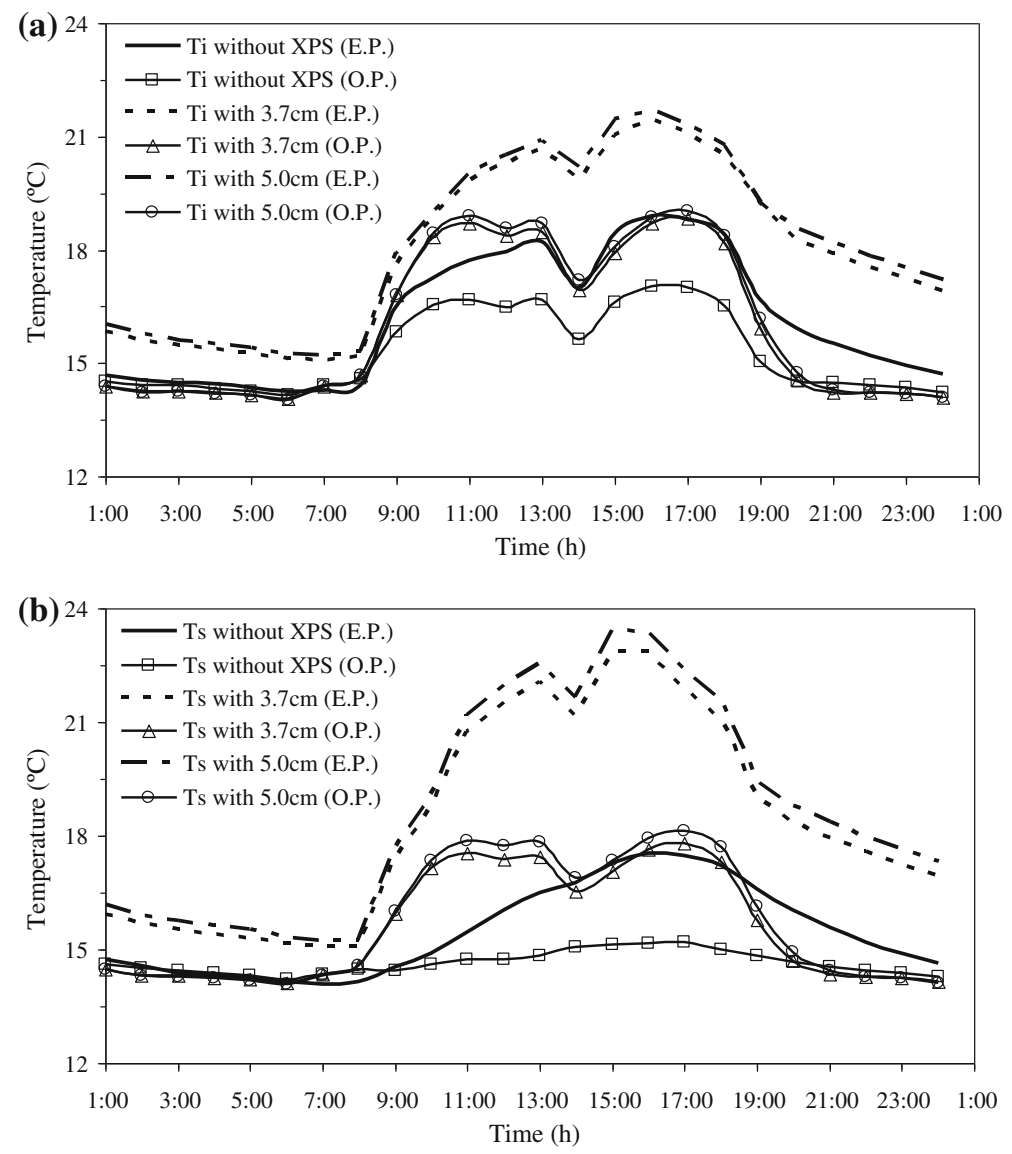

Fig. 12 Evolution of the (a) indoor temperature and (b) superficial indoor temperature on north façade, obtained by the optimization program (O.P.) and energy-plus (E.P.) with different insulation thicknesses, on January 13 
Table 1 Results of energy-plus simulations with different thicknesses of thermal insulation

\begin{tabular}{lcccccccccccc}
\hline $\begin{array}{l}\text { Insulation } \\
\text { thickness (cm) }\end{array}$ & & 0 & 1 & 2 & 3 & 4 & 5 & 6 & 7 & 8 & 9 \\
\hline $\mathrm{T}_{\min }$ & & 0.4 & 1.6 & 2.3 & 2.9 & 3.3 & 3.7 & 4.0 & 4.2 & 4.4 & 4.6 \\
$\mathrm{~T}_{\max }$ & 30.7 & 33.1 & 34.6 & 35.5 & 36.3 & 36.8 & 37.3 & 37.6 & 37.9 & 38.1 \\
$\begin{array}{l}\text { Results for an } \\
\quad \text { annual simulation }\end{array}$ & $\mathrm{P}_{5} \%$ & 7.5 & 8.8 & 9.7 & 10.2 & 10.6 & 10.9 & 11.2 & 11.4 & 11.6 & 11.7 \\
& $\mathrm{~T}_{\text {ave }}$ & 15.8 & 17.5 & 18.5 & 19.2 & 19.7 & 20.1 & 20.4 & 20.6 & 20.8 & 21.0 \\
& $\mathrm{P}_{95} \%$ & 23.6 & 26.0 & 27.4 & 28.3 & 29.0 & 29.5 & 29.9 & 30.3 & 306 & 30.8 \\
$\begin{array}{l}\text { No of days with } \\
\quad\end{array}$ & 33 & 12 & 4 & 2 & 1 & 1 & 1 & 1 & 1 & 0 \\
$\quad \begin{array}{l}\text { superficial condensations } \\
\text { of the walls }\end{array}$ & & & & & & & & & & \\
$\begin{array}{l}\text { No days with superficial } \\
\text { condensations on the ceiling }\end{array}$ & 126 & 22 & 4 & 4 & 1 & 1 & 1 & 1 & 1 & 0 \\
\hline
\end{tabular}

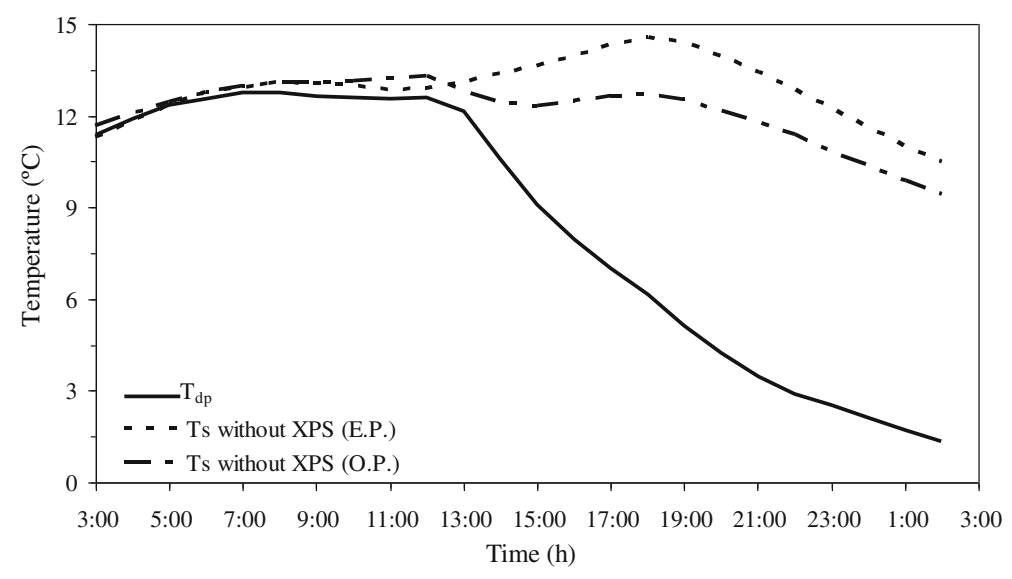

Fig. 13 Evolution of the superficial indoor temperature on north façade, obtained by the optimization program (O.P.) and energy-plus (E.P.), on December 29

\subsubsection{Case II: Model with Solar Gains}

January 4 and 25 were targeted for analysis as were the days with minimum and maximum radiation in that month (Fig. 14).

The Optimization Program, including solar gains and admitting the optimization of the window thermal resistance determined an insulation thickness of $4.5 \mathrm{~cm}$ and a $\mathrm{U}$ value of the window of $6.0 \mathrm{~W} / \mathrm{m}^{2} \mathrm{C}$. The temperatures assessed for that day, presented in Fig. 15 show a close course to the obtained in Energy plus. It's also possible to see that the period more severe for the determination of insulation thickness was the end of the day, after the students leave the room. Changing the windows demonstrated not to be relevant for the specific objective of this optimization case. 


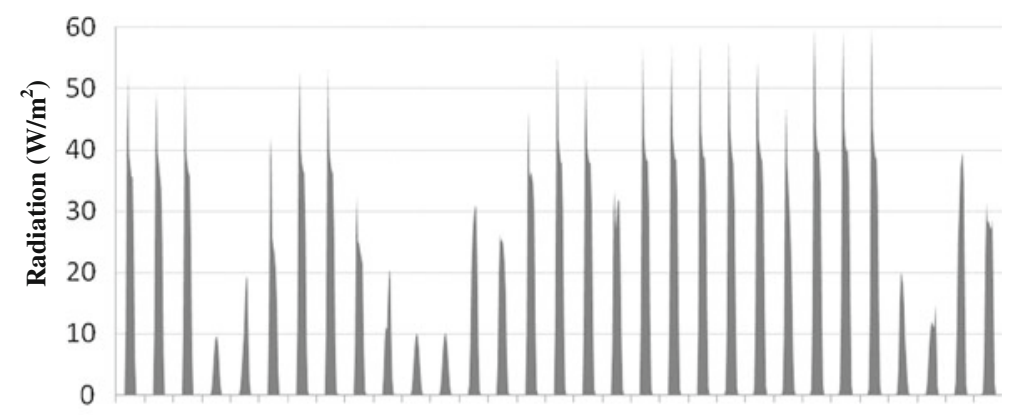

123455678910111213141516171819202122232425262728293031 Time (days)

Fig. 14 Radiation in January
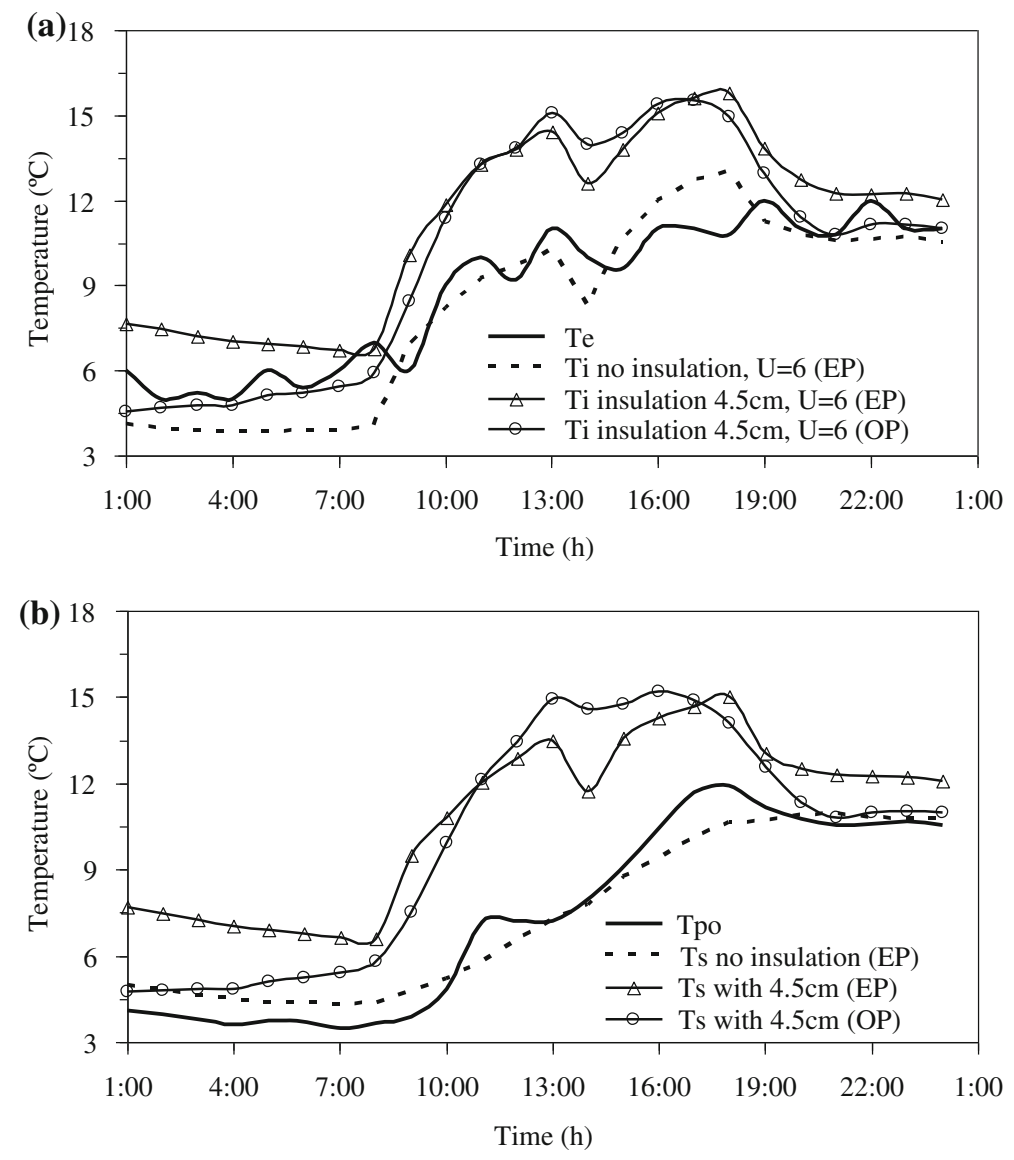

Fig. 15 Evolution of the (a) indoor temperature and (b) surface temperature, obtained by the optimization program (O.P.) and energy-plus (E.P.), on January 4 
The results of the hourly values of temperature obtained in O.P. and Energy Plus were also compared for January 25, as presented in Fig. 16. The modelling of that specific day didn't provide an agreement as good as before. In this specific day, solar radiation was important, leading to a not so good performance of O.P. simpler model. Nevertheless, solar gains were included, leading to the possibility of a first assessment of this scenario.

To understand how far the results of O.P. could be interesting for the determination of the optimal insulation thickness regarding surface condensation control, the building was simulated in E.P. for several envelope configurations. The results of those simulations are presented in Fig. 17. The results show that a small thickness of insulation added to the wall can make a huge difference in terms of
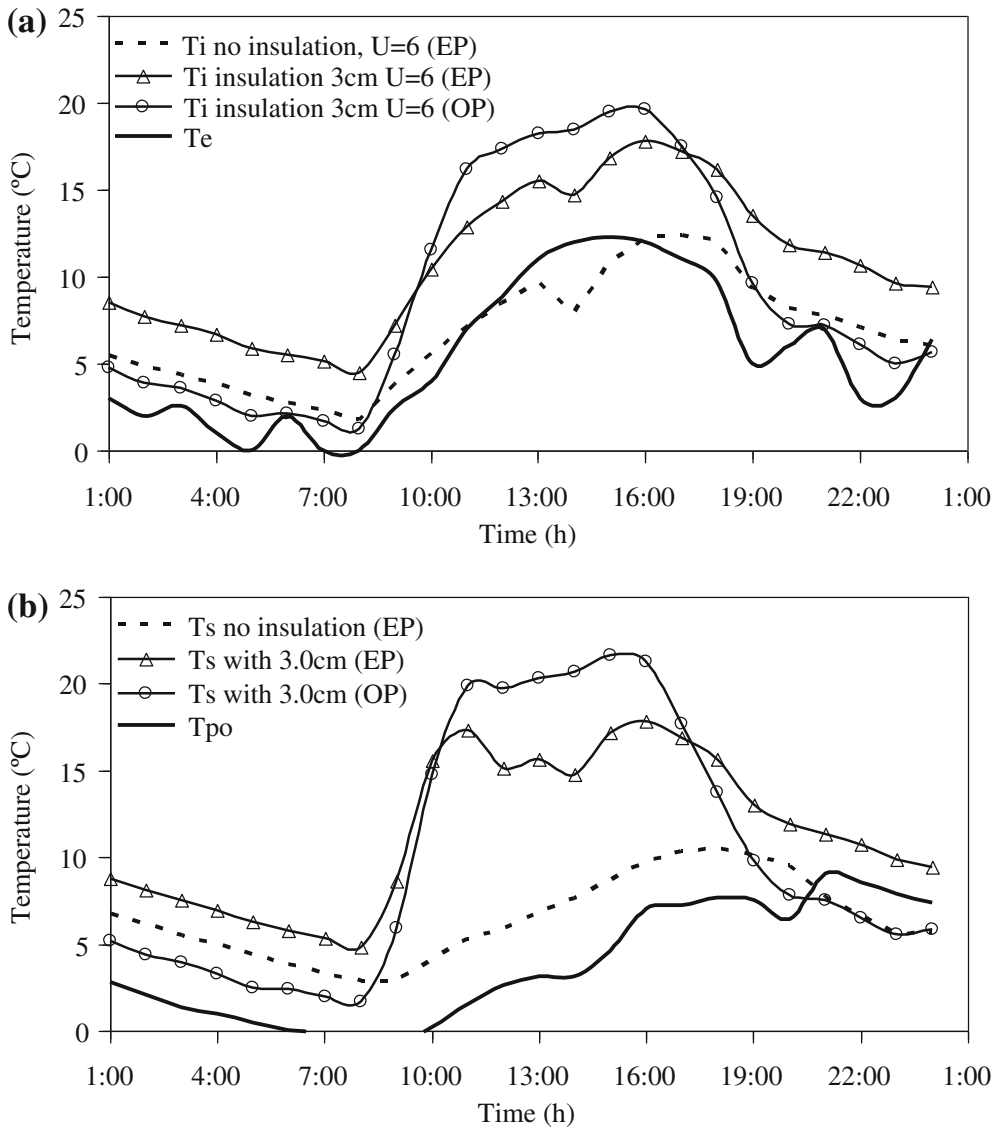

Fig. 16 Evolution of the (a) indoor temperature and (b) surface temperature, obtained by the optimization program (O.P.) and energy-plus (E.P.), on January 25 


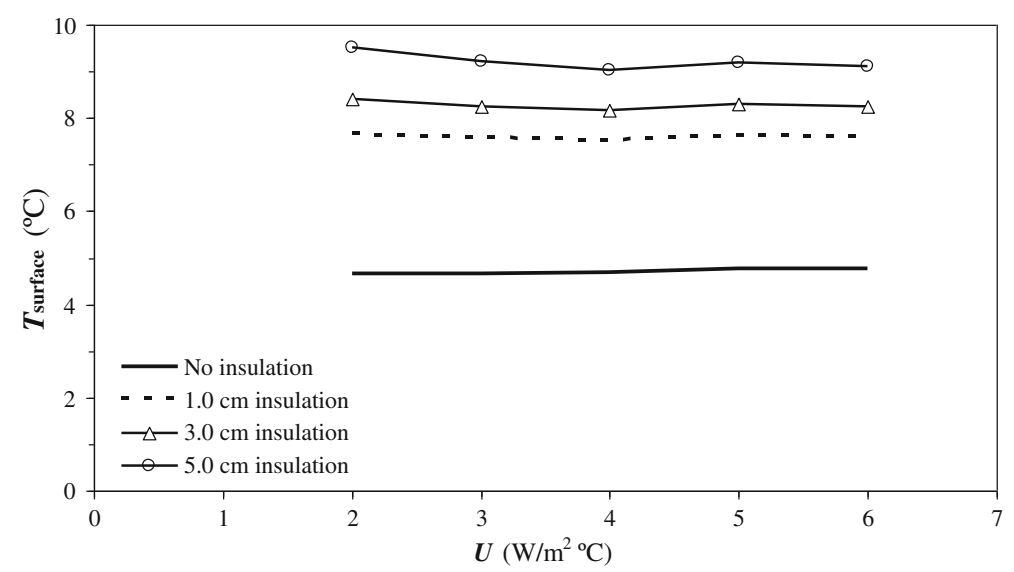

Fig. 17 Evolution of the superficial indoor temperature on north façade, obtained by the optimization program (O.P.) and energy-plus (E.P.), on December 29

resulting minimum surface temperature while the window resistance will have a very small influence. Hence, the O.P. pointed directly to a result that's feasible while considering, in a simplified model, the more relevant parameters to this problem.

\section{Conclusions}

Thermal comfort, energy efficiency, indoor air quality and durability must be analysed in depth for sensitive buildings of which schools are an example. A simple model, combined with an optimisation tool was able to provide a local optimal solution to the design of an envelope intended to prevent surface condensation. The scenario analysed in this example puts in evidence that a detailed analysis of the hourly hygrothermal behaviour can be very important. If a detailed analysis is available, the decision on using additional insulation will be based not only on energy efficiency versus comfort but also on durability aspects that can depend, for instance, on avoiding defacement caused by mould due to surface condensation.

In this specific case, it was shown how less than $3 \mathrm{~cm}$ additional insulation would be sufficient to reduce the risk of severe mould growth.

The optimization problem, consisting of minimizing a linear function on a set of linear and nonlinear constraints, using the solver MINOS of the commercial software GAMS proved to be an interesting aid for retrofit processes analysis. The limitations of the O.P. are linked to a not so perfect calculation if solar gains are included. 
A set of aspects must be added, however, so that a complete design methodology can be of use, providing a complete risk analysis scheme. Especially the stochastic nature of the hygrothermal processes must be included, leading to a non deterministic approach. The authors believe that the developed optimization program will be useful due to the linear functions adopted on simulation.

Acknowledgment J.M.P.Q. Delgado would like to thank Fundação para a Ciência e a Tecnologia (FCT) for financial support through the grant SFRH/BPD/84377/2012.

\section{References}

1. PMEES: Programa de Modernização das Escolas do Ensino Secundário, Resolução do Conselho de Ministros n $1 / 2007$, Lisboa, Portugal (in Portuguese) (2007)

2. SCE: Sistema nacional de certificação energética e da qualidade do ar interior nos edifícios, DL no 78/2006, Diário da República, I Série-A, Abril, Lisboa (in Portuguese) (2006)

3. RSECE: Regulamento dos sistemas energéticos de climatização dos edifícios, DL no 79/200 Diário da República, I Série-A, Abril, Lisboa (in Portuguese) (2006)

4. Grimsrud, D., Bridges, B., Schlte, R.: Continuous measurements of air quality parameters in schools. Build. Res. Inf. 34(5), 447-458 (2006)

5. Freitas, V.P.: Educational building retrofitting. In: Proceedings of the 3rd International Symposium on Building Pathology, Durability and Rehabilitation-PATORREB, Porto, Portugal (2009)

6. Holm, A., Hellwig, R., Sedlbauer, K.: Retrofitting of a school with an integral aspect. In: Proceedings of the 8th Nordic symposium of Building Physics, Copenhagen, Denmark (2008)

7. Jernberg, P., Sjöström, C., Lacasse, M.A.: TC 140-TSL: Prediction of service life of building materials and components (joint with CIB W80): State-of-the-art report. Mater. Struct. 30(1), 22-25 (1997)

8. Crawley, D.B., Lawrie, L.K., Winkelmann, F.C., Pedersen, C.O.: Energy-plus: energy simulation program. ASHRAE J. 42(4), 49-56 (2000)

9. Energy-Plus: Engineering reference. In Energy-Plus Documentation Main Menu (2009)

10. ISO 7730: Ergonomics of the thermal environment analytical determination and interpretation of thermal comfort using calculation of the PMV and PPD indices and local thermal comfort criteria. Switzerland (2005)

11. Robinson, S.M.: A quadratically-convergent algorithm for general nonlinear programming problems. Math. Program. 3(1), 145-156 (1972)

12. Murtagh, B.A., Saunders, M.A.: MINOS 5.1 User's Guide. Report SOL 83-20R (Revised), Department of Operations Research, Stanford University (1987)

13. Broke, A., Kendrick, D., Meeraus, A., Raman, R.: GAMS a User's Guide. GAMS Development Corporation, New York (1998) 